
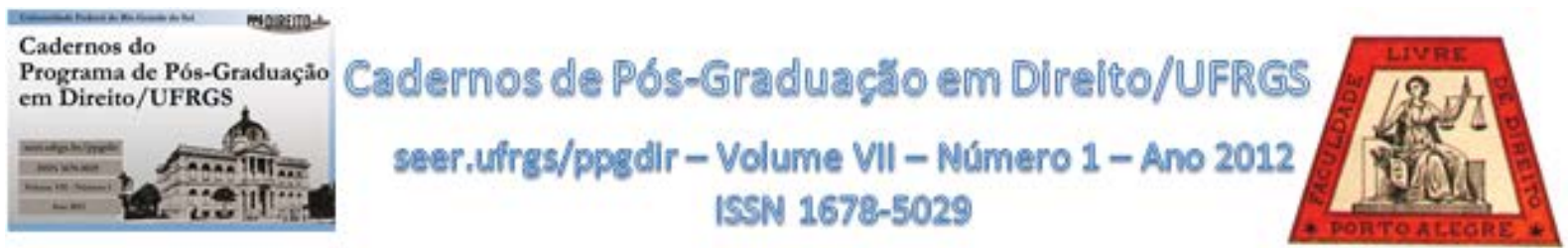

\title{
REVISITANDO O DEBATE SOBRE A EFICÁCIA DECLARATÓRIA DA SENTENÇA E A COISA JULGADA
}

\author{
REVISITING THE DEBATE ON THE DECLARATIVE EFFICACY OF THE SENTENCE AND RES \\ JUDICATA
}

Jonathan Doering Darcie

Sumário: Introdução: sobre a sentença e a natureza da função jurisdicional. 1. Sentença e coisa julgada. 2. Sobre as visões clássicas a respeito da coisa julgada. 3. A coisa julgada como declaração contida na sentença. 4. Sobre a coisa julgada como qualidade dos efeitos da sentença. 5. A polêmica entre Barbosa Moreira e Ovídio Baptista. Conclusão. Referências.

Resumo: Este escrito objetiva realizar uma análise a respeito do relacionamento existente entre a sentença, o seu elemento declarativo e a coisa julgada, com o enfrentamento crítico das posições mais tradicionais a respeito dos temas respectivos.

Palavras-chave: sentença; eficácia; eficácia declaratória; efeito; coisa julgada

Abstract: This article aims to realize an analysis of the relationships between the sentence, its declarative element and res judicata, with a critical review of the most traditional positions regarding the respective subjects.

Keywords: sentence; efficacy; declarative efficacy; effect; res judicata

\section{INTRODUÇÃO: SOBRE A SENTENÇA E A NATUREZA DA FUNÇÃO JURISDICIONAL}

Com esse pequeno escrito, objetiva-se trazer ao debate o tema da coisa julgada e do seu relacionamento com os possíveis conteúdos e decorrências da sentença, revisitando-se, com isso, sem renúncia a colocações de ordem crítica, um antigo debate no âmbito do direito processual civil.

Para que possa tratar o tema de modo sistemático e adequado, neste momento introdutório somos obrigados a estabelecer algumas posições sobre conceitos fundamentais envolvidos, sem os quais qualquer tentativa que pudéssemos empreender para o enfrentamento da matéria possivelmente restaria sem a completude necessária. Em especial, a natureza da sentença judicial e a função jurisdicional. 
Em uma monografia pouco conhecida, KATZ escreve sobre a sentença no processo civil austríaco, à época novo. Ali, faz algumas interessantes considerações a respeito da natureza da sentença. Segundo KATZ, no que nos interessa, "a sentença é a declaração judicial de existência ou inexistência da pretensão acionável (Klaganspruch)" ${ }^{1}$. Afirmará, em seguida, que "a sentença não cria direito novo, mas declara o direito já disponível" ${ }^{2}$. A partir dessas premissas, conclui que a sentença é declaratio, não constitutio ${ }^{3}$. Segundo essa visão, a sentença não constituiria ela própria direito, representando unicamente ato de reconhecimento do direito já previamente dado.

Pensava da mesma forma WinDSCHEID. Na visão do autor, a pretensão (Anspruch) reconhecida na sentença era precisamente a mesma introduzida no processo ao começo, com a diferença de que, naquele ponto, recebia do juiz a sua valoração definitiva:

A relação não é outra senão aquela introduzida como resultado do início do processo; através da sentença não é nulificada a pretensão já existente e colocada outra em seu lugar: ela recebe, a pretensão introduzida ao início, através da sentença, sua valoração definitiva. ${ }^{4}$

Os pontos de vista de WINDSCHEID e KATZ representam orientação teórica segundo a qual o processo, ou, no caso, a sentença, nada mais seria do que elemento de reconhecimento do direito, de certificação do já existente. Segundo os cultuadores desta visão, a sentença não cria (schaffen), mas, ao contrário, reconhece ou declara (feststellen) o direito que a ela préexiste.

A esta perspectiva da sentença como mera reconhecedora do direito já existente sobreveio interessante variação, a sustentar o ponto de vista de que a sentença seria elemento de criação de uma norma individual. Uma texto bastante tradicional a respeito foi escrito por BÜLOW, sob o título Gesetz und Richteramt, resultado de discurso que proferiu por ocasião do aniversário do rei Karl de Württemberg, em Tübingen, e a aula inaugural com a qual se habilitou como professor catedrático na Universidade de Leipzig. Segundo BüLOW, o direito legislado, posto pelos poderes do Estado, nada mais representaria do que um " é somente um plano, somente um projeto de um ordenamento jurídico futuro e desejado, o que por si mesmo o legislador pôde tornar acabado" ${ }^{5}$. Esse papel de concretização é deixado ao juiz, para que dê a medida da justiça, para que pondere e determine o que é certo ${ }^{6}$. Considera, por esta razão,

\footnotetext{
${ }^{1}$ KATZ, Heinrich. Das Urtheil im neuen österreichischen Civilprocesse. Wien: 1896, p. 27.

${ }^{2}$ KATZ, Heinrich. Das Urtheil im neuen österreichischen Civilprocesse. Wien: 1896, p. 27

${ }^{3}$ KATZ, Heinrich. Das Urtheil im neuen österreichischen Civilprocesse. Wien: 1896, p. 27

${ }^{4}$ WINDSCHEID, Bernhard. Lehrbuch des Pandektenrechts. 6 ${ }^{\mathrm{a}}$ ed.., t. I, Frankfurt a.M: 1887, p. 419.

${ }^{5}$ BÜLOW, Oskar. Gesetz und Richteramt. Leipzig: Verlag von Duncker \& Humbolt, 1885, p. 3.

${ }^{6}$ Ibidem, p. 4
} 
que a essência da função judicial se encontra na sentença ${ }^{7}$, que determina ou ordena o direito, como declaração de vontade do direito ${ }^{8}$.

A noção de sentença como entidade de criação do direito encontrou eco também nos escritos de KELSEN. Segundo o autor austríaco,

uma decisão judicial não tem, como por vezes é suposto, um caráter meramente declaratório. O tribunal não tem só de descobrir e declarar um direito já previamente fixado e pronto, de produção já finalizada. A função do tribunal não é só a "descoberta" do direito ou sua "dicção" neste sentido declaratório. A descoberta do direito consiste apenas na declaração sobre a norma geral aplicável ao caso concreto. E também esta declaração não tem só caráter declaratório, mas também constitutivo. ${ }^{9}$

Considera-se, em KELSEN, o estabelecimento da norma individual como parcela de um processo, que tem início na dação da norma superior até a execução da sanção inferiormente estabelecida ${ }^{10}$. Esta concretização, processo de permanente recriação do direito, é, segundo KELSEN, constantemente crescente $^{11}$. Assim, segundo o autor, o juiz é efetivamente instituição criadora do direito. Difere da legislação porque é outorga de direito em sentido abstrato, enquanto a sentença outorga de direito no sentido concreto.

A respeito da natureza da sentença e de sua função perante o direito tomou também posição Rocco. Segundo o jurista italiano, a sentença é "l'atto con cui lo Stato, a mezzo dell'organo della giurisdizione a ciò destinato (giudice), aplicando la norma al caso concreto, accerta quale tutela giuridica il diritto obiettivo concede a un determinato interesse ${ }^{12}$. Por esta razão, pensa que a sentença seja não um atto di volontà do juiz, tampouco uma dichiarazione di volontà por parte do mesmo, mas que a característica essencial da sentença seja o juízo lógico que enceta: a sentença é essencialmente - diz-se essencialmente porque Rocco não afasta a possibilidade de que concorram acidentalmente outros elementos $-{ }^{13}$ um atto della mente del giudice ${ }^{14}$. Afirma, de modo a tornar completa a sua formulação sobre a sentença, que a norma jurídica, embora pressuponha também um juízo lógico do órgão de qual emana, é, essencialmente, um atto di volontà, e precisamente, um comando dirigido do Estado ao indivíduo ${ }^{15}$. Este comando, sendo expresso de forma abstrata,

\footnotetext{
${ }^{7}$ Ibidem, p. 4

${ }^{8}$ Ibidem, p. 6

${ }^{9}$ KELSEN, Hans. Reine Rechtslehre. Mit einem Anhang: Das problem der Gerechtigkeit. 2a ed., Wien: Franz Deuticke, 1960, p. 243.

${ }^{10}$ Ibidem, p. 242.

${ }^{11}$ Ibidem, p. 242

${ }^{12}$ ROCCO, Alfredo. La sentenza civile. Torino: Fratelli Bocca, 1906, p. 32.

${ }^{13}$ Ibidem, p. 34

${ }^{14}$ Ibidem, p. 33.

${ }^{15}$ Ibidem, p. 34.
} 
deve necessariamente ser concretizado, o que ocorre através da sentença ${ }^{16}$. Para não incidir em contradição, afirma que esta operação de concretização não implica o ajuntamento de uma vontade própria (do juiz) à vontade já manifestada pelo órgão legislativo; esta operação, segundo a qual se determina qual a conduta que deve ser seguida pelo indivíduo, é meramente lógica, um silogismo, no qual figura como premissa maior a norma geral, premissa menor o caso concreto, sendo disto deduzida a norma de conduta a ser seguida no caso concreto ${ }^{17}$.

Algumas observações nossas devem ser aqui vertidas, especialmente a respeito da abrangência do anunciado caráter normativo da sentença. Sempre que a sentença meramente reconhece o direito, o declara, porque assim postulada a tutela jurisdicional, então seu conteúdo se resume a um juízo de ser, a retirar-lhe, portanto, aí, a condição de norma - norma individual. Um juízo é a ligação entre dois $\operatorname{conceitos~}^{18}$. Como tal, será primariamente a afirmação de que algo é ou não outra coisa, submetendo-se, assim, a um crivo veritativo (verdadeiro ou falso). Ao declarar, a sentença está dizendo que algo é ou não é; não representa, aqui citando KELSEN, um ato de vontade direcionado à conduta de outrem ordenando que algo deva acontecer ${ }^{19}$, mas meramente a predicação de algo, razão porque, enquanto meramente declaração, não pode ser considerada norma, não ao menos em sentido técnico. Se alguma conduta ocorre motivada pela declaração contida na sentença, então assim é porque o estado de coisas certificado pela sentença o determina. Age contrariamente ao direito o que exige o cumprimento de obrigação já reconhecida inexistente pela sentença porque há um suporte fático extraprocessual que o determina como ilícito. A declaração, nesse caso, é mero instrumento de certificação.

A sentença, como ato processual, é parcela de atuação da finalidade do processo civil. Esse possui um caráter instrumental, como instrumento para realização e asseguramento do direito material; é instrumento para a tutela jurídica, imediatamente, do patrimônio jurídico do indivíduo ${ }^{20}$, mediatamente, sempre, ao homem ${ }^{21}$.

\footnotetext{
${ }^{16}$ Ibidem, p. 34.

${ }^{17}$ Ibidem, p. 34.

${ }^{18}$ ARISTOTLE. The organon, or logical treatises. Vol. I. Trad. Octavius Freire Owen. London: George Bell \& Sons, 1889, p. 46-52.

${ }^{19}$ KELSEN, Hans. Teoria geral das normas. Trad. José Florentino Duarte. Porto Alegre: Sergio Antonio Fabris Editor, 1986, p. 2.

${ }^{20}$ OLIVEIRA, Carlos Alberto Alvaro de. Teoria e prática da tutela jurisdicional. Rio de Janeiro: Forense, 2008, p. 108.

${ }^{21}$ Trata-se de pequena variação a respeito do posicionamento adotado por ALVARO DE OLIVEIRA (nota n. 20). O dissenso consiste em que, conquanto nos pareça adequado que o processo seja instrumento para atuação da tutela jurisdicional imediatamente ao patrimônio jurídico, estará sempre mediatamente limitado, dado a natureza essencialmente normativa do direito (um ato de vontade), antropocentricamente. A proteção jurídica outorgada pelo direito à fauna e à flora, por exemplo, somente possui algum sentido enquanto algo antropocentricamente valorado, considerado, pela razão que for, como um interesse humano.Façamos uso de um exemplo. Imagine-se
} 
Dessa forma, parece evidente que uma sentença geralmente não será só a declaração do direito pré-existente, tanto quanto não será somente norma. Nosso ordenamento jurídico não é de todo auto-suficiente, embora possamos assumir a existência de ordenamentos jurídicos que o sejam. O negócio jurídico contraído em erro ou ignorância, por exemplo (artigos 138 e 139 do Código Civil), é causa de sua anulabilidade; esta não ocorre automaticamente, mas pressupõe a comunhão da vontade do interessado com a sentença do juiz. Não é a vontade o elemento de desconstituição do negócio jurídico, mas a sentença do juiz. Tanto é assim que, nesse caso, seus efeitos operam exclusivamente para frente. Outro exemplo é a condenação contida na sentença, decorrente de hipótese de responsabilidade civil extracontratual. A quantificação de uma indenização evidentemente depende de algo que, no caso do nosso ordenamento jurídico, não está contido na lei. É um ato de vontade, algo subjetivo, e não um mero silogismo que atribui valor a um fato jurídico abstrato. De outro modo, seria o juiz um oráculo da justiça, sendo sua tarefa a extração de verdades a partir de uma realidade imanente.

Paralelamente, há elementos auto-suficientes no nosso ordenamento jurídico. A existência de cláusula resolutiva expressa no negócio jurídico, tornada eficaz, implica que a atividade judicial a ela relacionada seja exclusivamente de declaração, de reconhecimento, de certificação de algo já existente. Nesta dimensão, a sentença não é norma e não produz algo novo que não certeza e, através dela, a estabilidade.

Toda esta introdução para afirmarmos que a sentença é ato jurídico que, no mais das vezes, contém elementos normativos e juízos. Os juízos estão sempre presentes, uma vez que é de sua natureza a predicação, a atribuição de uma qualidade a alguma coisa. O elemento normativo, no entanto, posto que apareça frequentemente, não é obrigatório. As sentenças meramente declaratórias ou de improcedência, pois, são sentenças destituídas de característica normativa, não encetando no mundo jurídico normas particulares de qualquer espécie. Não

um homem que vive em um mundo onde sabe estar só, não havendo nem outros homens nem animais capazes de comportamento social complexo. Há, neste mundo hipotético, flora e fauna como as que conhecemos. Nesse cenário pensado, podemos tranquilamente afirmar que não apenas não haveria razão para a existência de direito como, ademais, seria impossível a existência do direito, ao menos no sentido de um direito não natural. O direito existe como instrumento criado pelo homem em sociedade para condicionamento da conduta do homem que dela participa. Fala-se, aqui, pois, em heteronomia, hetero-nomos. Se não há pluralidade homens, o direito perde sua razão finalística de ser. Se o homem que, no nosso exemplo, vive sozinho, estabelece como regra que não infligirá qualquer tipo de violação à integridade física de animais, então ele o faz por razões próprias, sejam elas quais forem. Não se tratam de normas exteriores que condicionam a sua conduta, mas de normas internas, intencionadas pelo próprio homem. Fala-se, aqui, em autonomia , auto-nomos. Nesse último caso, não podemos falar em direito, mas exclusivamente em moral, pois nesse caso falamos do agir em seu aspecto interior, o agir em respeito à 'lei' moral' apenas em razão da consciência (KANT, Immanuel. Metaphisik der Sitten. F. Meiner, 1966. p. 24-25). 
quer dizer que não produzam efeitos ou mesmo representem, como fatos jurídicos, fundamento para normas jurídicas. Apenas que, em si mesma, a sentença declaratória pura não constitui ordem de qualquer espécie.

De outro lado, a consequência óbvia de reconhecer ao juiz a posição de criador do direito, ainda que no sentido individual, reside na constatação de que o ordenamento jurídico não é auto-suficiente.

\section{SOBRE AS VISÕES CLÁSSICAS A RESPEITO DA COISA JULGADA}

Uma perspectiva tradicional do processo civil esteve sempre vinculada à idéia de uma auto-suficiência do ordenamento jurídico. Em SAVIGNY, por exemplo, na sua clássica concepção do direito de ação como uma metamorfose do direito material, resultante do binômio direito em si mais violação (Recht an sich mais Verletzung) ${ }^{22}$, fica clara essa compreensão do fenômeno processual. Se o meu acesso ao processo era constituído pelo próprio direito material transformado, então é óbvio que, do processo, nada diferente poderia emanar além do próprio direito material certificado. A coisa julgada estava, então, estritamente vinculada a esta idéia de processo como ferramenta de certificação do direito, na linha das considerações que traçamos no início da exposição.

Os primeiros desenvolvimentos que verificamos a respeito da coisa julgada são aqueles em que a identificaram como uma presunção da verdade ${ }^{23}$. Segundo UlPIANO, "Ingenuum accipere debemus etiam eum, de quo sententia lata est, quamvis fuerit libertinus: quia res iudicata pro veritate accipitur." ${ }^{24}$ Essa tendência de assunção da sentença como verdade perdurou, verificando-se, por exemplo, nas lições de Sigismondo Scaccia:

sententia quae transit in rem iudicatam habetur ex praesumptione iuris et de iure pro veritate;res iudicata facit de albo nigrurn, originem creat, aequat quadrata rotundis, naturalia sanguinis vincula et falsum in verum mutat. ${ }^{25}$

Essa visão da coisa julgada como presunção esteve presente inclusive em Pothier, que considerava a autoridade da coisa julgada como presunção de direito e de fato da verdade $^{26}$.

\footnotetext{
${ }^{22}$ SAVIGNY, Friedrich Carl von. System des heutigen römischen Rechts. T. V, Berlin: 1841, p. 6.

${ }^{23}$ ESTELLITA, Guilherme. Da cousa julgada: fundamento juridico e extensão aos terceiros. Rio de Janeiro: 1936, p. 26.

${ }^{24}$ DIGESTA, 1.5.25.

${ }^{25}$ SCACCIA, Sigismondo. Tractatus de sententia et re judicata. 1670, p. 376.
} 
A questão tomou desenvolvimento um pouco diverso em SAVIGNY, no que se poderia definir como um meio-caminho entre a dogmática clássica e os desenvolvimentos modernos $^{27}$. Na visão de SAVIGNY ${ }^{28}$, não seria extraordinário, incomum, que uma sentença pudesse ser proferida em uma apreciação equivocada ou do direito ou dos fatos, dando gênese a uma solução inadequada para um caso concreto $^{29}$. Se seguiria que, muito provavelmente, seria cassada por uma sentença contendo um juízo contrário. Esta alteração, no entanto, não implicaria necessariamente o sossego da situação em questão. Um juiz ainda posterior, convencido da existência de um error na segunda sentença, poderia anulá-la e trazer novamente à vigência a primeira ou, ainda, expressar uma terceira opinião, diversa da contida nas primeiras duas sentenças. Como resultado, enquanto possível que uma relação jurídica constituísse objeto de apreciação em um processo posterior, imperaria a mais absoluta insegurança ${ }^{30}$.

A respeito deste cenário, afirma SAVIGNY:

Desta observação decorre que temos diante de nós dois sérios perigos de natureza oposta. De um lado se encontra o perigo de que devemos ter como direito a sentença prolatada pelo juiz em erro ou de má-fé, mesmo quando podemos reconhecer com toda a convicção a injustiça. Do outro lado o perigo de uma incerteza sem limites a respeito de relações patrimoniais e jurídicas, que podem perdurar por várias gerações. ${ }^{31}$

Entre estas duas possibilidades, ou, como diz, perigos, devemos optar. Trata-se, pois, de uma questão de política do direito ${ }^{32}$. Pois as legislações e sistemas jurídicos tomaram partido neste dilema e, desde muito, vem reconhecendo na insegurança jurídica o mal maior a ser evitado, ainda que com sacrifício de uma denominada "justiça". Este cenário deu origem ao que SAVIGNY denominou de mais importante instituto jurídico destinado à atuação desta finalidade, qual seja, de securitização do direito: a Rechtskraft der richtelichen Urtheile, ou força do direito da sentença judicial, por nós conhecida como a coisa julgada ${ }^{33}$. Para SAVIGNY, a coisa julgada representava a ficção da verdade (Fiction der Wahrheit), através da qual protegeria-se a sentença tornada coisa julgada contra qualquer tentativa futura de sua

\footnotetext{
${ }^{26}$ POTHIER, Robert Joseph. Tratado das obrigações. Tradução de Witt Batista e Douglas Dias Ferreira. Campinas: Servanda, 2001, p. 725-726.

${ }^{27}$ Ver, nesse ponto, CHIOVENDA, Giuseppe. Saggi di diritto processuale civile: 1894-1937. Vol. II, Milano: Giuffrè, 1993, p. 400; ROCCO, Ugo. L'autorità della cosa giudicata e i suoi limiti soggettivi. Roma: Athenaeum, 1917, p. 29.

${ }^{28}$ Também, em mesmo sentido, ROSENBERG, Leo. Lehrbuch des deutschen Zivilprozessrechts. $3^{\mathrm{a}}$ ed., Berlin: Otto Liebmann, 1931, p. 517.

${ }^{29}$ SAVIGNY, Friedrich Carl von. System des heutigen römischen Rechts. T. VI, Berlin: 1847, p. 259-260.

${ }^{30}$ Ibidem, p. 259-260.

${ }^{31}$ Ibidem, p. 260.

${ }^{32}$ Ibidem, p. 260.

${ }^{33}$ Ibidem, p. 261.
} 
contestação ou invalidação ${ }^{34}$. O instituto da coisa julgada significa, pois, o asseguramento para todo o futuro da eficácia do conteúdo de cada sentença ${ }^{35}$.

Como ficção de verdade que é, a coisa julgada pode repercutir seriamente sobre o ordenamento jurídico. Pode declarar existente direito onde não havia, negar direito onde antes havia ou alterar conteúdo de direito já existente ${ }^{36}$. Finalmente, SAVIGNY aponta a existência particular de três efeitos da coisa julgada, a saber: a execução, a actio iudicati e a exceção da coisa julgada ${ }^{37}$.

O pensamento de SAVIGNY gerou certa repercussão, sendo também adotado por outros autores. Em ARNDTS vON ARNESBERG, clássico da pandectística alemã, percebe-se a influência das palavras de SAVIGNY: “A sentença judicial deve pôr fim ao litígio. Por isso a regra: o que é pronunciado através de sentença com coisa julgada sobre o direito litigado das partes vale como verdade; a sentença estabelece direito formal." ${ }^{38}$

Estas percepções da coisa julgada, seja como presunção seja como ficção da verdade, encetam uma série de problemas, graves o suficiente para que se as tenha como incapazes de explicar adequadamente o instituto da coisa julgada.

O sentido da coisa julgada enquanto presunção da verdade falha na medida em que atribui à sentença mero papel de enunciadora do direito. Uma sentença declaratória, segundo a opinião que já manifestamos, não representa norma jurídica, mas enceta um juízo, expresso linguisticamente através da estrutura de uma proposição. Toda a proposição (Satz) é uma estrutura linguística consistente em uma relação entre dois objetos ${ }^{39}$. Sendo uma proposição de natureza enunciativa (Aussagesatz), poderá conter uma ligação entre um objeto e uma propriedade ou, também, um modo de comportamento ${ }^{40}$. Proposições são, assim, estruturas linguísticas determinadas à atuação de uma das funções da linguagem, a descrição ${ }^{41}$, de modo que estão submetidas à valoração veritativa (verdadeiro ou falso) ${ }^{42}$.

\footnotetext{
${ }^{34}$ Ibidem, p. 261.

${ }^{35}$ Ibidem, p. 300.

${ }^{36}$ Ibidem, p. 263.

${ }^{37}$ Ibidem, p. 409.

${ }^{38}$ ARNDTS VON ARNESBERG, Karl Ludwig. Lehrbuch der Pandecten. München: 1852, p. 153.

${ }^{39}$ LARENZ, Karl. Methodenlehre der Rechtswissenschaft. $3^{\mathrm{a}}$ ed., Berlin: Springer, 1995, p. 72.

${ }^{40}$ Ibidem, p. 72.

${ }^{41}$ WITTGENSTEIN, Ludwig. Tractatus Logico-Philosophicus. São Paulo: Companhia Editora Nacional, 1968, p. 63-72, especialmente p. 72

${ }^{42}$ Como refere Lourival Vilanova, as proposições são "asserções de que algo é algo, de que tal objeto tem a propriedade tal. Estruturas de linguagem expressivas de proposições são suscetíveis de valores (verdade/falsidade), empiricamente verificáveis por qualquer sujeito que se ponha em atitude cognoscente" (VILANOVA, Lourival. As estruturas lógicas e o sistema do direito positivo. São Paulo: Ed. Revista dos Tribunais, EDUC, 1977, p. 3).
} 
Se é verdade que toda a sentença enceta um certo conteúdo declaratório - positivo ou negativo -, eventualmente não se limitará a ele. A sentença poderá conter, como já afirmamos anteriormente, uma norma concreta. Ocorre que, as normas jurídicas, dado o seu caráter deontológico, não se submetem a juízo veritativo, mas se sujeitam a um juízo de validade ${ }^{43}$ : ou valem ou não valem.

Enquanto se assuma que a sentença pode conter certo conteúdo normativo, a coisa julgada, na medida em que se queira a esse conteúdo normativo estender, não pode ser assumida como mera presunção da verdade.

Como bem notara FISCHER, já em 1889, "Não se trata de uma ficção da verdade, mas da autoridade da sentença judicial, no interesse da necessidade de segurança jurídica". ${ }^{44}$ Esta perspectiva da sentença enquanto expressão da verdade somente guardaria algum sentido se colocada a questão na dimensão da sentença enquanto prova, a pressupor, então, perspectiva de uma nova relação jurídica.

A posição de SAVIGNY, da coisa julgada como sendo ficção da verdade, pode ser mais ainda destinatária de críticas. Além daquelas exteriorizadas em relação à visão da coisa julgada como presunção da verdade, deve-se ter em mira que processo não é instrumento ontologicamente direcionado à busca da verdade, muito embora seja recomendável que essa atividade seja de algum modo realizada no curso do seu desenvolvimento ${ }^{45}$. De modo que, para atingir à sua finalidade, seu resultado não necessita constituir expressão ou conteúdo de verdade, real ou ficta. A verdade representa a pertinência de uma predicação em relação a determinada observação. De modo que, ficção da verdade, representaria, em último plano, uma contradição em termos.

\section{SOBRE A COISA JULGADA COMO A DECLARAÇÃO CONTIDA NA SENTENÇA}

O desenvolvimento teórico por que foi responsável HELLWIG a respeito da definição da coisa julgada foi bastante expressivo. Com seu Wesen und subjektive Begrenzung der

\footnotetext{
${ }^{43}$ KELSEN, Hans. Teoria geral das normas. Trad. José Florentino Duarte. Porto Alegre: Sergio Antonio Fabris Editor, 1986, p. 36-37.

${ }^{44}$ FISCHER, Otto. Recht und Rechtsschutz. Berlin: 1889, p. 135.

${ }^{45}$ A questão é absolutamente polêmica e desafia a mais variada literatura a respeito. Por essa razão, além do fato de transbordar o escopo do presente escrito, deixamos em aberto a análise da literatura e minudenciamento dos pontos de vista respectivo.
} 
Rechtskraft, HELLWIG recebeu grande adesão por parte da comunidade jurídica, em grande parte em razão da precisão e lógica com que desenvolveu as suas idéias.

Segundo HELLWIG, os atos jurisdicionais através dos quais os órgãos do poder estatal atendem ao papel do processo civil - que consiste, explica, na concessão da proteção ao direito privado - são ou atos de declaração (Festellungsakte) ou atos constitutivos

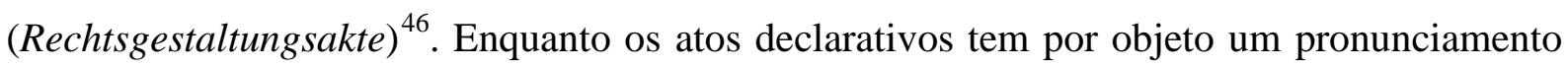
sobre existência ou inexistência da relação jurídica que compõe o objeto do julgamento, os atos constitutivos intencionam modificar o estado no âmbito do direito civil ou processual (den vorhandenen civilrechtlichen oder prozessualen Rechtszustand verändern), com a pretensão de gerar novos efeitos jurídicos ${ }^{47}$.

A modificação jurídica (Rechtsgestaltung) compõe o conteúdo imediato e característico da sentença constitutiva, advertindo o autor, no entanto, que o seu significado aí não se esgota ${ }^{48}$. Aqui reside um ponto central da construção de HeLlWIG. Entende que, na medida em que o tribunal faz uso do poder de ordem estatal para pronunciar a mudança jurídica pretendida pela ação que a quis fazer valer, existe nela implícita a declaração sobre o direito à modificação jurídica, à constituição, da mesma forma que a rejeição do direito alçado a objeto do processo representa a negação de sua existência ${ }^{49}$.

Deste modo, assim que a sentença constitutiva se transforma em coisa julgada, a modificação jurídica ocorre, neste momento se realizando - em um sentido de exaurimento o direito à modificação jurídica ${ }^{50}$. Portanto, a sentença constitutiva tornada coisa julgada não mais poderá ser utilizada para justificar a alegação da existência (presente) do direito à modificação jurídica, como, por exemplo, do direito ao divórcio já consumado. Em verdade, esse conteúdo declaratório da sentença constitutiva tem o significado de declarar que o direito do demandante existia, também que a modificação jurídica deu-se em conformidade com o direito $^{51}$.

$\mathrm{Na}$ sentença condenatória, que é tida como uma 'modalidade' da sentença constitutiva $^{52}$, ocorre fenômeno análogo, uma vez que contém, de um lado, a declaração da obrigação de prestar (Festellung der Leistungspflicht), e, de outro, seu conteúdo imperativo, a ordem de prestar (Leistungsbefehl).

\footnotetext{
${ }^{46}$ HELLWIG, Konrad. Wesen und subjektive Begrenzung der Rechtskraft. Reimp. ed. 1901. AAlen: Scientia Verlag, 1967, p. 1.

${ }^{47}$ Ibidem, p. 1.

${ }^{48}$ Ibidem, p. 3.

${ }^{49}$ Ibidem, p. 3-4.

${ }^{50}$ Ibidem, p. 4.

${ }^{51}$ Ibidem, p. 4.

${ }^{52}$ LIEBMAN, Enrico Tullio. Efficacia ed Autorità della Sentenza. Milano: Giuffrè, 1962, p. 11-12.
} 
Com estas premissas traçadas, HELLWIG sustenta que a coisa julgada não é instituto propriamente de direito material mas, sobretudo, de direito processual ${ }^{53}$. Segundo pensa, a coisa julgada material não é um conceito de direito material, mas se posiciona como um efeito jurídico puramente processual ${ }^{54}$.

Assim disposta a questão por HellwiG, de que modo visualiza a coisa julgada? A declaração contida na sentença traz, segundo afirma, certeza jurídica para as partes ${ }^{55}$. Esta segurança, pois, a declaração a respeito de ser ou não fundada a pretensão que se quis fazer valer com a ação (ou, de modo mais preciso, a demanda, Klagantrag), desde que a decisão não possa mais ser atacada no processo em curso, é que se torna inquestionável perante qualquer outro juiz ${ }^{56}$. Uma vez definitiva a decisão sobre o estado jurídico existente, então o direito processual proíbe os tribunais de perquirirem ${ }^{57}$ a respeito da correção da decisão ${ }^{58}$. Do segundo juiz, diz HELLWIG, não se é de esperar de modo algum que acredite na correção do estado jurídico declarado; está ele, no entanto, vinculado à declaração: ele deve ter como fundamento em sua nova decisão o novo estado jurídico declarado, ainda que a incorreção da decisão seja de clareza solar (sonnenklar) ${ }^{59}$.

Na visão de HELLWIG, portanto, a coisa julgada material consiste na indiscutibilidade que recai sobre a declaração contida na sentença após o seu trânsito em julgado. Essa orientação teórica gerou, como antes referido, um sem número de seguidores. Entre eles,

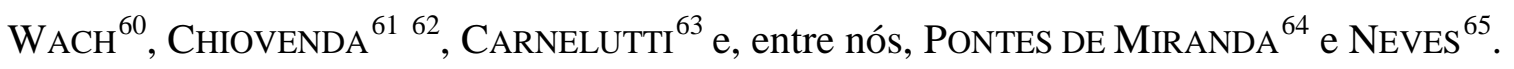

\footnotetext{
${ }^{53}$ HELLWIG, Konrad. Wesen und subjektive Begrenzung der Rechtskraft. Reimp. ed. 1901. AAlen: Scientia Verlag, 1967, p. 7-10.

${ }^{54}$ Ibidem, p. 10.

${ }^{55}$ Ibidem, p. 12.

${ }^{56}$ Ibidem, p. 12.

${ }^{57} \mathrm{O}$ autor chega a falar em "importunar", behelligen.

${ }^{58}$ Ibidem, p. 12.

${ }^{59}$ Ibidem, p. 12.

${ }^{60}$ WACH, Adolf. LABAND, Paul. Zur Lehre von der Rechtskraft. Leipzig: 1899, p.4 e 8.

${ }^{61}$ CHIOVENDA, Giuseppe. Instituições de direito processual civil. Trad. J. Guimarães Menegale. Vol. I. São Paulo: Saraiva, 1945, p. 514-515. CHIOVENDA, Giuseppe. Saggi di diritto processuale civile. 1894-1937. Vol. II, Milano: Giuffrè, 1993, p. 399.

${ }^{62}$ A posição de Chiovenda é referida por LieBMAn (LIEBMAN, Enrico Tullio. Efficacia ed Autorità della Sentenza. Milano: Giuffrè, 1962, p. 10).

${ }^{63}$ A afirmativa de CARNLUTTI não nos deixa dúvidas a respeito de sua orientação: "la immutabilità della decisione risponde non già al suo carattere imperativo, ma alla sua funzione dichiarativa". (CARNELUTTI, Francesco. Lezioni di diritto processuale civile. T. IV. Padova: Litotipo, 1933, p. 93).

${ }^{64}$ PONTES DE MIRANDA, Francisco Cavalcanti. Comentários ao código de processo civil. $1^{\mathrm{a}}$ ed., t. II, Rio de Janeiro: Forense, 1947, p. 378. PONTES DE MIRANDA, Francisco Cavalcanti. Comentários ao código de processo civil. $1^{\text {a }}$ ed., vol. V, Rio de Janeiro: Forense, 1948, p. 143-144; 151-155.

${ }^{65}$ NEVES, Celso. Coisa julgada civil. São Paulo: Revista dos Tribunais, 1971, p. 497-504.
} 


\section{SOBRE A COISA JULGADA COMO UM ATRIBUTO DOS EFEITOS DA SENTENÇA}

A mais relevante oposição à identificação da coisa julgada material com o efeito declaratório da sentença partiu de LiEBMAN. Na verdade, o seu Efficacia ed Autorità della Sentenza representa um verdadeiro levante particularmente contra o desenvolvimento que deu ao problema da coisa julgada HeLLWIG.

Depois de algumas breves considerações sobre o estado da doutrina até então, LIEBMAN inicia sua crítica afirmando que consiste um erro lógico sistematizar a coisa julgada ao lado dos outros possíveis efeitos da sentença, uma vez que, assim procedendo, se colocam em mesmo plano coisas heterogêneas e de qualidade bem diversa ${ }^{66}$. A identificação da declaração jurisdicional com a autoridade da coisa julgada, a compenetração de uma na outra, a redução da eficácia da primeira à segunda, afirmará a seguir, constitui um erro de perspectiva, algo, ademais, que se explicaria psicologicamente no fato de que a incontestabilidade que a autoridade da coisa julgada outorga ao resultado do processo apresenta-se de modo mais marcantemente necessário no caso da declaração, visto que, mutável ou contestável, a declaração se apresentaria inútil e destituída de importância: "si può cioè riconoscere che un accertamento privo di autoritá del giudicato è, per chi l'ha ottenuto, poco meno che inutile" ${ }^{67}$.

Entende, no entanto, que estas observações não infirmam de modo algum a constatação de que a declaração contida numa sentença deriva sua força obrigatória, ou, mais genericamente, sua eficácia jurídica, da natureza imperativa e autoritativa do ato que a produz, tanto quanto o seria a força decorrente de uma sentença constitutiva ${ }^{68}$. É dizer, não haveria razão para se ter a eficácia constitutiva da sentença como um minus em relação ao seu possível conteúdo declaratório.

A partir dessas observações, LiEBMAN passa a desenvolver sua tese a respeito da existência de uma diferença entre os efeitos da sentença e sua perenidade, características que se relacionam como objeto e qualidade. Afirma que "altro è distinguere gli effetti dela sentenza secondo la loro natura dichiarativa o constitutiva, altro è vedere se essi si

\footnotetext{
${ }^{66}$ LIEBMAN, Enrico Tullio. Efficacia ed Autorità della Sentenza. Milano: Giuffrè, 1962, p. 13.

${ }^{67}$ Ibidem, p. 13.

${ }^{68}$ Ibidem, p. 13-14.
} 
producano in modo più o meno perpetuo e immutabile." ${ }^{69}$ Segundo pensa, a coisa julgada é um algo que se agrega aos efeitos da sentença, para a eles acrescer estabilidade ${ }^{70}$.

Para demonstrar cabalmente que a coisa julgada constitui algo ontologicamente distinto dos efeitos da sentença, uma qualidade que os envolve, LIEBMAN exterioriza a constatação de que os efeitos da sentença se manifestam antes do seu trânsito em julgado ${ }^{71}$. A existência dos efeitos da sentença antes de seu trânsito em julgado é uma constante para todos os seus efeitos, sejam eles declaratórios, condenatórios ou constitutivos ${ }^{72}$. Afinal, "si deve cioè riconoscere in linea logica che l'effeto di accertamento o costitutivo che una sentenza può produrre è ben diversa cosa dalla possibilità maggiore o minore che esso, una volta prodotto, possa essere contestato, infirmado o revocato". ${ }^{73}$ A incontestabilidade é um caractere logicamente não necessário que pode ser conferido ao efeito mesmo sem modificar a sua própria e íntima natureza, conclui ${ }^{74}$.

Direcionando conclusivamente sua crítica a HELLWIG, afirma que, quando esse identifica a coisa julgada como efeito específico da sentença quando não mais passível de impugnação, e, "più precisamente come l'efficacia di accertamento della sentenza"75, confunde o efeito normal da sentença com a definitividade e incontestabilidade do mesmo.

Embora constante no prefazione, com esta relevante passagem de LIEBMAN sintetiza a essência do seu pensamento a respeito da natureza da coisa julgada e ao conteúdo sobre o qual se estende:

La funzione giurisdizionale ha un contenuto più complesso, più ricco o più vario di quello della semplice soluzione di una questione dubbia. La certezza è, sì, componente essenziale della giustizia, ma non la esaurisce. E la sentenza, in cui culmina l'ufficio del giudice, non crea soltando certezza, ma produce spesso (anzi, nel più gran numero dei casi) anche altri effetti, praticamente di grande rilevo, i quali tutti non possono essere rimossi quando la sentenza acquisiti l'autorità della cosa giudicata. Perciò quest'autorità non può riferirsi ad uno solo tra i possibili effetti della sentenza, bensì a tutti unitariamente e non può avere altro significato, se non quello di indicare un modo di essere, una qualità di quegli effettii. ${ }^{76}$

A coisa julgada não seria, pois, para LIEBMAN, em uma síntese do seu pensamento, um efeito mas, ao contrário, uma qualidade contingente dos efeitos da sentença judicial.

\footnotetext{
${ }^{69}$ Ibidem, p. 14.

${ }^{70}$ Ibidem, p. 14.

${ }^{71}$ Ibidem, p. 26.

${ }^{72}$ Ibidem, p. 26.

${ }^{73}$ Ibidem, p. 26.

${ }^{74}$ Ibidem, p. 26.

${ }^{75}$ Ibidem, p. 28.

${ }^{76}$ Ibidem, p. IV-V, prefazione.
} 


\section{A POLÊMICA ENTRE JOSÉ CARLOS BARBOSA MOREIRA E OVÍDIO BAPTISTA DA SILVA}

As conclusões a que chegou LIEBMAN em sua monografia geraram repercussão. Seja para infirmá-la ou acolhê-la, no total ou em parte, a visão da coisa julgada material como qualificativo dos efeitos da sentença tornou-se ponto de enfrentamento obrigatório para os juristas que pretendiam investir no assunto.

Entre nós, a monografia provocou a existência de um célebre debate, havendo como protagonistas José CARlos Barbosa Moreira e Ovídio A. BAPTISTA DA SiLVA.

Em relação à visão desses dois juristas a respeito da coisa julgada, é comum a ambas o fato de acolherem as conclusões de LIEBMAN sobre a coisa julgada constituir não um elemento da sentença mas, entendida como criação do sistema vocacionada à estabilização, à segurança jurídica, como um qualificativo de determinado conteúdo da sentença. Veja-se em BAPTISTA DA SILVA: "Liebman tem razão quando afirma que a coisa julgada não é propriamente um efeito da sentença, mas uma qualidade posterior que ao efeito se ajunta, para torná-lo imutável"77. Da mesma forma em BARBOSA MOREIRA: "Bem consideradas as coisas, não é difícil compreender quão inadequadamente se descreve a realidade dos fatos quando se diz que a sentença, ao transitar em julgado, produz o efeito de tornar-se indiscutível. Tal é, no fundo, muito ao contrário, um efeito que a sentença recebe, um efeito que sobre ela se produz." ${ }^{78}$ Nesse sentido, ainda que em medidas diversas, ambos discordam da orientação de HELLWIG, que vê na coisa julgada a própria declaração contida na sentença. Por aí, no entanto, findam as concordâncias.

Segundo BARBOSA MOREIRA, haveria um certo artificialismo na construção de HellWig a respeito da coisa julgada, no ponto em que a vincula a atribuição de incontestabilidade exclusivamente ao "elemento declaratório da sentença". Seu questionamento assim o indica: "Por que há de convir á declaração, e não convir à modificação, o atributo da incontestabilidade?"79 Na sua visão, não há razão para "negar dose equivalente de certeza à modificação acaso operada pela sentença. Se um juiz anula um contrato, por exemplo, fica o resultado do processo, após o trânsito em julgado, menos imune à contestação do que ficaria se ele se limitasse a delcarar nulo o contrato?" ${ }^{80}$. Para BARBOSA MOREIRA, pois, a autoridade da coisa julgada é a imunidade da sentença a contestações

\footnotetext{
${ }^{77}$ BAPTISTA DA SILVA, Ovídio Araujo. Sentença e coisa julgada. Porto Alegre: Fabris, 1995, p. 104.

${ }^{78}$ MOREIRA, José Carlos Barbosa. Temas de direito processual civil. São Paulo: Saraiva, 1977, p. 88.

${ }^{79}$ MOREIRA, José Carlos Barbosa. Temas de direito processual civil. São Paulo: Saraiva, 1977, p. 82.

${ }^{80}$ Ibidem, p. 82.
} 
juridicamente relevantes ${ }^{81}$, sendo, então, como já anteriormente referido, uma qualidade da sentença, pois que "A eficácia da sentença e a sua imutabilidade suscitam duas ordens de questões inconfundíveis e, em linha de princípio, autônomas" ${ }^{82}$, de modo que a "imutabilidade não é co-natural à sentença" ${ }^{83}$. A imutabilidade, em harmonia com o pensamento de LiEBMAN, SAVIGNY, CHIOVENDA e outros, não é algo inerente à declaração judicial, mas algo que a ela se agrega por conveniência. ${ }^{84}$

A sentença judicial, como ato jurídico que é, possui certo conteúdo ${ }^{85}$. São as eficácias da sentença que, na visão de BARBOSA MoREIRA, constituem o conteúdo da sentença $^{86}$. E o que são, pois, tais eficácias ou conteúdo da sentença? Por eficácia, diz, entenda-se a "palavra que se costuma usar, na linguagem jurídica, para designar a qualidade do ato enquanto gerador de efeitos" ${ }^{87}$. Segundo BARBOSA MOREIRA, a sentença, como todo ato jurídico, destina-se a produzir efeitos no mundo jurídico ${ }^{88}$, cabendo à lei, no entanto, a fixação do ponto exato em que estes passarão a ocorrer ${ }^{89}$, de modo que, segundo a sua construção, a sentença é ato jurídico dotado de eficácia ou conteúdo. Os efeitos do ato jurídico, afirma, não formam o interior, mas lhe são exteriores: "de modo algum isso significa que o efeito produzido pelo ato se identifique ou se confunda com o respectivo conteúdo, ou faça parte desse conteúdo. O efeito é algo que está necessariamente, por definição, fora daquilo que o produz, que se trate de fato natural, que de ato jurídico." ${ }^{90}$ Daí porque, como ato jurídico que é,

o que se disse dos atos jurídicos em geral diz-se igualmente, em particular, da sentença. Também quanto a esta se distinguem um conteúdo, algo que está nela, que a integra, e vários efeitos que, nascendo nela, se manifestam fora, se projetam ad extra. Esses efeitos variam segundo o conteúdo, são determinados por ele, mas nem por isso com ele se confundem. 91

\footnotetext{
${ }^{81}$ Ibidem, p. 88.

${ }^{82}$ MOREIRA, Barbosa. Eficácia da sentença e autoridade da coisa julgada. in Revista Brasileira de Direito Processual. Vol. XXXII. Uberaba: Forense, p. 44.

${ }^{83}$ Ibidem, p. 44.

${ }^{84}$ Ibidem, p. 45.

${ }^{85}$ MOREIRA, Barbosa. Conteúdo e efeitos da sentença: variações sobre o tema. in Revista Brasileira de Direito Processual. Vol. XXXXVI. Uberaba: Forense, p. 93.

${ }^{86}$ Ibidem, p. 94.

${ }^{87}$ Ibidem, p. p. 94.

${ }^{88}$ MOREIRA, Barbosa. Eficácia da sentença e autoridade da coisa julgada. in Revista Brasileira de Direito Processual. Vol. XXXII. Uberaba: Forense, p. 45.

${ }^{89}$ Ibidem, p. 43.

${ }^{90}$ MOREIRA, Barbosa. Conteúdo e efeitos da sentença: variações sobre o tema. in Revista Brasileira de Direito Processual. Vol. XXXXVI. Uberaba: Forense, p. 94.

${ }^{91}$ Ibidem, p. 95.
} 
No caso da sentença condenatória, seu efeito seria o de ensejar a execução; na sentença constitutiva, conviveriam, dentro da mesma sentença, o reconhecimento do direito à modificação - aqui, ressaltamos, na mesma linha do sustentado por HELLWIG - e a modificação enquanto ato (a anulação, etc.). ${ }^{92}$ A esta modificação enquanto ato seguiria a modificação enquanto efeito, a representar o resultado da atuação deste conteúdo determinado na sentença: com a anulação do contrato, por exemplo, surgiria o novo estado jurídico dele decorrente ${ }^{93}$.

Entendendo, pois, que os efeitos decorrentes da sentença serão sempre mutáveis ${ }^{94}$, afirma que "a imutabilidade consequente ao trânsito em julgado reveste, em suma, o conteúdo da sentença, não os seus efeitos. Reveste, convém frisar, todo o conteúdo decisório. [...] É toda a norma jurídica concreta que se torna imutável." ${ }^{95}$

Em BARBOSA MOREIRA, parece haver uma identificação entre conteúdo da sentença e norma concreta. Veja-se que afirma que "Toda sentença, meramente declaratória ou não, contém a norma jurídica concreta que deve disciplinar a situação submetida à cognição judicial" 96 . Igualmente, quando afirma que "os efeitos da sentença não se tornam imutáveis com o trânsito em julgado: o que se torna imutável (ou, se se prefere, indiscutível) é o próprio conteúdo da sentença, como norma jurídica concreta referida à situação sobre que se exerceu a atividade congitiva do órgão judicial" ${ }^{97}$.

A visão de BAPTISTA DA SILVA é diversa. O jurista, questionando as conclusões de LIEBMAN de que todos os efeitos da sentença estariam sujeitos à qualificação pela coisa julgada, afirma que se sujeitam naturalmente à modificação as eficácias (ou efeitos) da sentença, com exceção do declaratório ${ }^{98}$. Diz que, "se os efeitos constitutivos ou condenatórios podem desaparecer sem ofensa à coisa julgada, parece lógico concluir-se que a imutabilidade só tenha referência ao que foi declarado, à eficácia declaratória da sentença" ${ }^{\prime 99}$.

Posto que nos primeiros escritos transite livremente entre os conceitos de eficácia e efeito, a sugerir que os tem por equivalentes ${ }^{100}$, coloca-se, em ensaio posterior, a dintingui-

\footnotetext{
${ }^{92}$ Ibidem, p. 95-96.

${ }^{93}$ Ibidem, p. 96.

${ }^{94}$ Ibidem, p. 49.

${ }^{95}$ MOREIRA, Barbosa. Eficácia da sentença e autoridade da coisa julgada. in Revista Brasileira de Direito Processual. Vol. XXXII. Uberaba: Forense, p. 52.

${ }^{96}$ Ibidem, p. 47.

${ }^{97}$ MOREIRA, José Carlos Barbosa. Temas de direito processual civil. São Paulo: Saraiva, 1977, p. 89.

${ }^{98}$ BAPTISTA DA SILVA, Ovídio Araujo. Sentença e coisa julgada. Porto Alegre: Fabris, 1995, p. 104-106.

${ }^{99}$ Ibidem, p. 105.

${ }^{100}$ Várias passagens assim o justificam (Ibidem, p. 104-106).
} 
$\operatorname{los}^{101}$. Afirma, pois, que a categoria das eficácias "faz parte do 'conteúdo' da sentença, com virtualidade operativa capaz da produção de efeitos, ao passo que estes, quer se produzam no mundo jurídico, quer no mundo dos fatos hão de ter-se como atualizações no sentido aristotélico, das eficácias"102. As eficácias, afirma, "fazem parte do 'conteúdo da sentença', assim como se diz que este ou aquele medicamento possui tais ou quais virtudes (ou eficácias) curativas" 103 .

Com estas colocações, BAPTISTA DA SILVA nega a possibilidade de uma separação entre o plano normativo e os efeitos dele decorrentes. Para ele, tanto os efeitos se produzem efetivamente em cada sentença, quanto as eficácias que os tornam possíveis, também existem e constam das sentenças concretas ${ }^{104}$.

Em suma, BAPTISTA DA SILVA rechaça a possibilidade de a coisa julgada acobertar o total dos efeitos ou eficácias da sentença, tornando-os imutáveis. Somente a eficácia declaratória é que, com a sobrevinda da coisa julgada, ganharia a condição de inquestionável.

\section{CONCLUSÃO}

Apesar de termos tecido algumas críticas a certos conceitos tradicionais de sentença e da coisa julgada ao longo deste escrito, deixamos para o final a oportunidade para a emissão de um juízo a respeito dos desenvolvimentos posteriores sobre a coisa julgada. Antes de o fazermos, mostra-se importante retomar as posições fundamentais expostas ao longo do trabalho.

Como visto anteriormente, apesar de alguma oscilação entre autores a respeito do escopo da sentença em relação ao direito, é dizer, se a função da sentença é de meramente reconhecer o direito pré-existente ou de criá-lo concretamente, não há dúvidas de que, na prática, cada uma das formulações representam parcela da verdade. Toda a sentença contém, obrigatoriamente, um juízo a respeito da existência do direito ou interesse pleiteado. Trata-se da eficácia declaratória. Enquanto mecanismo de reconhecimento, a eficácia declaratória da sentença não constitui norma concreta e, por essa razão, não cria direito. Concorrendo mais de uma eficácia na mesma sentença, então haverá nesse ato judicial uma norma, cujo papel

\footnotetext{
${ }^{101}$ Ibidem, p. 214.

102 Ibidem, p. 214.

103 Ibidem, p. 214.

${ }^{104}$ Ibidem, p. 215-216.
} 
será o de concretizar o direito material, integrando, sempre que necessário, elementos outros para a formação do direito concreto.

Com essa formação, não se pode atribuir às decorrências da coisa julgada o papel de presunção ou ficção da verdade. Além de não ser escopo central do processo a busca da verdade, esta visão a respeito da coisa julgada seria incompatível com as sentenças em que múltiplas são as eficácias, quando, então, poderíamos estar diante de uma norma concreta, porque as normas não se sujeitam a juízos veritativos mas de validade.

De SAVIGNY até BAPTISTA DA SILVA, houve uma notável evolução no trato teórico da coisa julgada, com contribuições sendo lançadas a cada nova geração de escritos. Algumas restaram descartadas, como visto, em razão de ilogicidades ou da sua incapacidade de bem explicar a realidade jurídica. Toda a sentença contém um juízo sobre a existência do direito ou do interesse debatido em juízo. Tem razão Hellwig quando afirma que essa declaração é o fundamento da sentença, a base para a existência de outras eficácias - o autor, em seus escritos, assumia a existência apenas de duas, a declaratória e a constitutiva, com a condenação sendo uma variação desta última. No entanto, parece ser igualmente verdadeiro que, segundo nos mostra LIEBMAN, a coisa julgada não pode ser entendida como um elemento da sentença. Se é possível pensar nos efeitos da sentença atuando normalmente, mas mutáveis, então à imutabilidade, à autoridade da coisa julgada, resta meramente a posição de qualidade dos efeitos da sentença.

Parece-nos, no entanto, que a imutabilidade proporcionada pela coisa julgada não poderia alcançar todo o complexo de efeitos da sentença. Não há dúvidas, refira-se inicialmente, que os efeitos da sentença serão sempre mutáveis. O titular de crédito decorrente de condenação judicial pode perdoar seu devedor ou o próprio devedor pode pagar a sua dívida. O divorciado pode alterar seu status jurídico casando-se novamente.

Com relação às eficácias, a questão ganha em complexidade. Por eficácia deve ser entendido, apropriando-nos do que dissera BARBOSA MoreIRA, a qualidade do ato enquanto capaz de gerar efeitos ${ }^{105}$. Por exemplo, eficácia constitutiva da sentença é a capacidade de alterar o estado jurídico de alguém, sendo a alteração o seu efeito. Se assumimos como correta a orientação de BARBOSA MoreIRA a respeito da coisa julgada, então somos obrigados a sustentar que todo o conteúdo da sentença e, portanto, suas eficácias, tornam-se imutáveis com o aparecimento da coisa julgada.

\footnotetext{
105 MOREIRA, Barbosa. Conteúdo e efeitos da sentença: variações sobre o tema. in Revista Brasileira de Direito Processual. Vol. XXXXVI. Uberaba: Forense, p. 94.
} 
O problema com que nos deparamos em função da construção de BARBOSA MOREIRA é que ela não parece se ajustar bem à realidade, ou, por outro lado, a realidade provocaria uma turbação na precisão dos conceitos adotados pelo autor. Pensemos em um simples exemplo: João paga a Maria o valor de R\$1.000,00, referente à condenação com trânsito em julgado que sofrera em processo de conhecimento anterior. Nesse cenário, se Maria postular o cumprimento da sentença, para o fim de obrigar João ao pagamento dos R\$ 1.000,00, João tranquilamente obstaculizará a pretensão de Maria, alegando pagamento (inciso VI, artigo 475-L do Código de Processo Civil). Mas se a eficácia condenatória resta intacta por força da coisa julgada, como explicar essa sua incapacidade superveniente de gerar efeitos, considerando que a possibilidade de postular execução é um desses efeitos? Na visão de LIEBMAN, esse problema se explicaria em razão de que toda a sentença contém implícita uma cláusula rebus sic stantibus ${ }^{106}$. Entretanto, a simples e elegante solução do jurista italiano, ainda que pareça adequada à primeira vista, verdadeiramente não resolve o problema, porque gera uma distorção considerável na idéia de imutabilidade da sentença. Ao admitirmos como veraz a asserção de LIEBMAN, então veremos que a sentença e seu conteúdo não é efetivamente imutável. Na verdade, o conteúdo da sentença seria facilmente mutável, bastando, para tanto, a ocorrência de fatos futuros a ele relacionados, como, no nosso exemplo, o pagamento.

Realmente, parece que a melhor solução para o conceito de coisa julgada reside em um aproveitamento de parcela das contribuições de HELLWIG, LiEBMAN e BAPTISTA DA SILVA. Na verdade, BAPTISTA DA SILVA resolvera bem a questão, tendo apenas faltado ao seu desenvolvimento a adequada precisão conceitual para a sua tese. A indiscutibilidade que decorre da coisa julgada é uma qualidade da eficácia declaratória da sentença, tornando-a imutável e insuscetível de debate juridicamente relevante. Veja-se que toda a sentença contém obrigatoriamente uma declaração, dentro da qual reside o juízo emitido pelo julgador a respeito da existência do direito ou interesse juridicamente relevante alegado pelo demandante. Pense-se no caso de uma sentença constitutiva de divórcio. Embora a alteração postulada do estado jurídico decorra da eficácia constitutiva, essa somente existiu porque, anteriormente, o julgador emitiu seu juízo a respeito da existência do direito ao divórcio. Existe, portanto, uma relação de dependência entre as demais eficácias e a eficácia declaratória da sentença. Ainda que, no caso do nosso exemplo, as partes divorciadas possam

106 "In un certo senso tutte le sentenze contengono implicitamente la calusola rebus sic standibus, in quanto la cosa giudicata non impedisce affato che si tenga conto dei fatto intervenuti sucessivamente all'emanazione della sentenza: ad esempio, se il debitore paga la somma dovuta, la condanna perde ogni valore" (LIEBMAN, Enrico Tullio. Efficacia ed Autorità della Sentenza. Milano: Giuffrè, 1962, p. 14). 
alterar novamente o seu estado jurídico, jamais poderão rediscutir judicialmente a existência, àquele tempo e naquelas condições, do direito ao divórcio, à mudança do estado jurídico.

Ao consideramos a imutabilidade como qualidade exclusiva da eficácia declarativa da sentença, tornamos o juízo ali emitido imutável, insuscetível de futura discussão. Os efeitos da sentença estarão, no mais das vezes, disponíveis às partes, da mesma forma que as eficácias, em razão de atos também das partes, podem perder a sua condição essencial, que é a capacidade para produção de efeitos jurídicos.

\section{REFERENNCIAS}

ARISTOTLE. The organon, or logical treatises. Vol. I. Trad. Octavius Freire Owen. London: George Bell \& Sons, 1889.

ARNDTS VON ARNESBERG, Karl Ludwig. Lehrbuch der Pandecten. München: 1852.

BAPTISTA DA SILVA, Ovídio Araujo. Sentença e coisa julgada. Porto Alegre: Fabris, 1995.

BÜLOW, Oskar. Gesetz und Richteramt. Leipzig: Verlag von Duncker \& Humbolt, 1885.

CARNELUTTI, Francesco. Lezioni di diritto processuale civile. T. IV. Padova: Litotipo, 1933.

CHIOVENDA, Giuseppe. Instituições de direito processual civil. Trad. J. Guimarães Menegale. Vol. I. São Paulo: Saraiva, 1945.

CHIOVENDA, Giuseppe. Saggi di diritto processuale civile: 1894-1937. Vol. II, Milano: Giuffrè, 1993.

ESTELLITA, Guilherme. Da cousa julgada: fundamento juridico e extensão aos terceiros. Rio de Janeiro: 1936.

FISCHER, Otto. Recht und Rechtsschutz. Berlin: 1889.

HELLWIG, Konrad. Wesen und subjektive Begrenzung der Rechtskraft. Reimp. ed. 1901. AAlen: Scientia Verlag, 1967.

KANT, Immanuel. Metaphisik der Sitten. F. Meiner, 1966.

KATZ, Heinrich. Das Urtheil im neuen österreichischen Civilprocesse. Wien: 1896.

KELSEN, Hans. Reine Rechtslehre. Mit einem Anhang: Das problem der Gerechtigkeit. 2a ed., Wien: Franz Deuticke, 1960.

KELSEN, Hans. Teoria geral das normas. Trad. José Florentino Duarte. Porto Alegre: Sergio Antonio Fabris Editor, 1986.

KELSEN, Hans. Teoria geral das normas. Trad. José Florentino Duarte. Porto Alegre: Sergio Antonio Fabris Editor, 1986. 
LARENZ, Karl. Methodenlehre der Rechtswissenschaft. $3^{\text {a }}$ ed., Berlin: Springer, 1995.

LIEBMAN, Enrico Tullio. Efficacia ed Autorità della Sentenza. Milano: Giuffrè, 1962.

MOREIRA, Barbosa. Conteúdo e efeitos da sentença: variações sobre o tema. in Revista Brasileira de Direito Processual. Vol. XXXXVI. Uberaba: Forense.

MOREIRA, Barbosa. Eficácia da sentença e autoridade da coisa julgada. in Revista Brasileira de Direito Processual. Vol. XXXII. Uberaba: Forense.

MOREIRA, José Carlos Barbosa. Temas de direito processual civil. São Paulo: Saraiva, 1977.

NEVES, Celso. Coisa julgada civil. São Paulo: Revista dos Tribunais, 1971.

OLIVEIRA, Carlos Alberto Alvaro de. Teoria e prática da tutela jurisdicional. Rio de Janeiro: Forense, 2008.

PONTES DE MIRANDA, Francisco Cavalcanti. Comentários ao código de processo civil. $1^{\mathrm{a}}$ ed., t. II, Rio de Janeiro: Forense, 1947.

PONTES DE MIRANDA, Francisco Cavalcanti. Comentários ao código de processo civil. $1^{\text {a }}$ ed., vol. V, Rio de Janeiro: Forense, 1948.

POTHIER, Robert Joseph. Tratado das obrigações. Tradução de Witt Batista e Douglas Dias Ferreira. Campinas: Servanda, 2001.

ROCCO, Alfredo. La sentenza civile. Torino: Fratelli Bocca, 1906.

ROCCO, Ugo. L'autorità della cosa giudicata e i suoi limiti soggettivi. Roma: Athenaeum, 1917.

ROSENBERG, Leo. Lehrbuch des deutschen Zivilprozessrechts. $3^{\text {a }}$ ed., Berlin: Otto Liebmann, 1931.

SAVIGNY, Friedrich Carl von. System des heutigen römischen Rechts. T. V, Berlin: 1841.

SAVIGNY, Friedrich Carl von. System des heutigen römischen Rechts. T. VI, Berlin: 1847.

SCACCIA, Sigismondo. Tractatus de sententia et re judicata. 1670.

ULPIANUS, DIGESTA, 1.5.25.

VILANOVA, Lourival. As estruturas lógicas e o sistema do direito positivo. São Paulo: Ed. Revista dos Tribunais, EDUC, 1977.

WACH, Adolf. LABAND, Paul. Zur Lehre von der Rechtskraft. Leipzig: 1899.

WINDSCHEID, Bernhard. Lehrbuch des Pandektenrechts. 6ª ed.., t. I, Frankfurt a.M: 1887.

WITTGENSTEIN, Ludwig. Tractatus Logico-Philosophicus. São Paulo: Companhia Editora .Nacional, 1968 